\title{
Human cognition assessment in drug research
}

Citation for published version (APA):

Riedel, W. J., Mehta, M. A., \& Unema, P. J. A. (2006). Human cognition assessment in drug research. Current Pharmaceutical Design, 12, 2525-39. https://doi.org/10.2174/138161206777698882

Document status and date:

Published: 01/01/2006

DOI:

10.2174/138161206777698882

Document Version:

Publisher's PDF, also known as Version of record

Document license:

Taverne

Please check the document version of this publication:

- A submitted manuscript is the version of the article upon submission and before peer-review. There can be important differences between the submitted version and the official published version of record.

People interested in the research are advised to contact the author for the final version of the publication, or visit the DOI to the publisher's website.

- The final author version and the galley proof are versions of the publication after peer review.

- The final published version features the final layout of the paper including the volume, issue and page numbers.

Link to publication

\footnotetext{
General rights rights.

- You may freely distribute the URL identifying the publication in the public portal. please follow below link for the End User Agreement:

www.umlib.nl/taverne-license

Take down policy

If you believe that this document breaches copyright please contact us at:

repository@maastrichtuniversity.nl

providing details and we will investigate your claim.
}

Copyright and moral rights for the publications made accessible in the public portal are retained by the authors and/or other copyright owners and it is a condition of accessing publications that users recognise and abide by the legal requirements associated with these

- Users may download and print one copy of any publication from the public portal for the purpose of private study or research.

- You may not further distribute the material or use it for any profit-making activity or commercial gain

If the publication is distributed under the terms of Article $25 \mathrm{fa}$ of the Dutch Copyright Act, indicated by the "Taverne" license above, 
See discussions, stats, and author profiles for this publication at: https://www.researchgate.net/publication/6943889

\section{Human Cognition Assessment in Drug Research}

Article in Current Pharmaceutical Design · February 2006

DOI: 10.2174/138161206777698882 · Source: PubMed

CITATIONS

20

3 authors:

Wim J Riedel

Maastricht University

149 PUBLICATIONS 7,250 CITATIONS

SEE PROFILE

Pieter Unema

Technische Universität Dresden

21 PUBLICATIONS 600 CITATIONS

SEE PROFILE

Some of the authors of this publication are also working on these related projects:

Project Ketamine Study View project

Project Create new project "beliefs and values inventory" View project
READS

385

Mitul A Mehta

King's College London

293 PUBLICATIONS 10,727 CITATIONS

SEE PROFILE 


\title{
Human Cognition Assessment in Drug Research
}

\author{
Wim J. Riedel ${ }^{1,2,3, *}$, Mitul A. Mehta ${ }^{4,5}$ and Pieter J. Unema ${ }^{2}$
}

${ }^{1}$ Psychiatry Discovery Medicine, GlaxoSmithKline R\&D, Cambridge, UK; ${ }^{2}$ Dept. of Neurocognition, Faculty of Psychology, Maastricht University, NL; ${ }^{3}$ Dept. of Psychiatry, University of Cambridge, UK; ${ }^{4}$ Centre for Neuroimaging Sciences, Institute of Psychiatry, King's College, London, UK and ${ }^{5}$ PET Psychiatry group, MRC Clinical Sciences Centre, Hammersmith Hospital, Imperial College, London, UK

\begin{abstract}
In this article cognition assessments as outcome measures in CNS drug development research are described. An outline is given of the various choices that can be made and the reasons for them, depending on the approach followed. First, a brief historical context is provided of the psychological sciences that have contributed to today's psychopharmacology of cognition assessment. Subsequently, the focus is on identifying cognitive domains and criteria for selecting appropriate tests.

In applied cognitive performance assessment in human psychopharmacology, a number of approaches can be recognised, each associated with models that connect cognitive functions with physiological functions and neural structures. The product-oriented approach of cognition assessment is usually characterised by the use of a battery of several cognitive tasks as an assessment instrument and aims to demonstrate an effect of a pharmaceutical substance without much attempt to determine which cognitive process is primarily influenced by a drug. The process-oriented approach precisely defines the cognitive process in terms of at least a single factor linear model of a process (e.g. by manipulating levels of difficulty) and then compares how diseases and drugs modify the parameters of that process. The associated factor analytical-, resource-strategy- and staged information processing models respectively are described. Finally a brief review is presented on possible physiological markers or biomarkers of human cognitive functions.
\end{abstract}

\section{INTRODUCTION}

The aim of this article is to present a rationale for cognition assessments as outcome measures in CNS drug development research. An outline is given of the various choices that can be made and the reasons for them, depending on the approach followed. Although various forms of functional brain imaging can be regarded as paradigms to study proxy markers of cognitive processes or functions as well, the focus of this paper will be on measures of cognitive performance, i.e. cognitive tests or tasks. First, a brief historical context is provided of the psychological sciences that have contributed to today's psychopharmacology of cognition assessment. Subsequently, the focus is on identifying cognitive domains and criteria for selecting appropriate tests.

\section{SOME HISTORICAL NOTES: NEUROPSYCHOLOGY}

Neuropsychology emerged from clinical psychology by describing abnormal behaviours in neurological patients. Classic cases with focal brain lesions helped to emerge an early generation of behavioural neuroscience in which brain was strictly considered as causative physical substrate and measurable behaviours as its consequence. In early days, crude measures of skull proportions such as size of the skull, and particularly brain weight were understood as most important markers of intellectual capacity. Later, one began to consider functional brain activity rather than the bare morphological properties of brains. Moreover, the topics of

*Address correspondence to this author at the GlaxoSmithKline, Addenbrooke's Centre for Clinical Investigation, Addenbrookes Hospital, Hills Road, Box 128, Cambridge CB2 2GG, UK; E-mail: willem.riedel@gsk.com interest shifted to the relation between brain pathology (such as commotio cerebri, dementia, multiple sclerosis, Huntington's chorea, Parkinson's and Korsakoff's syndromes) and deficiencies of intellectual performance. The search for correlations between specific brain morphology and psychiatric diseases such as psychotic disorders for example, has recently revived, due to the advent of neuroimaging techniques. Degenerative diseases in which disintegration of the prefrontal cortex was thought to explain clinical symptoms of intellectual decline were first described in the beginning of the 20th century (e.g. Alzheimer's Disease, Schizophrenia). Reaction times to learned words were assessed already in the 1880 s by means of morse code printers and a timing device (chronoscope), which was driven by an electric magnet. In those days the first publications about the effects of drugs (alcohol, caffeine, bromine and paraldehyde) on the acquisition of verbal material were carried out [1]. The finding that small quantities of champagne improved reaction time while large quantities slowed it down, probably still holds today. This is not the case pertaining to the acute effect of alcohol on memory of newly learned information: it could not be demonstrated in the 1901 experimental psychology lab, whereas nowadays blood alcohol levels as low as $.030 \mathrm{~g} / \mathrm{dl}$ (equivalent to $1-2$ consumptions) can be shown to impair cognitive and psychomotor performance [2], or even to retroactively enhance the memory of information learned prior to consumption [3]. In brief, the basis that Neuropsychology provided consists of the experimental model that irreversible or slowly reversible brain lesions (concussions) as well as quickly reversible brain lesions (alcohol and drugs) as independent variables can explain changes in behaviour and 'cognitive performance' as dependent variables. 
Neuropsychology has yielded a variety of tests tapping cognitive functions that each correspond with a particular region in the brain.

\section{BEHAVIOURISM AND EXPERIMENTAL PSYCHO- LOGY}

According to B F Skinner, the leading exponent of the school of psychology known as behaviourism, the behaviour of humans and other animals can be explained in terms of the physiological responses of the organism to external stimuli [4]. Behaviourists relied on purely descriptive, yet formal mathematical methods, to express all observable behaviours as functions of stimuli. Non-observable behaviours such as thoughts and consciousness were not considered entities because means to measure them were lacking. Complex behaviours that could imply thought and consciousness such as language were considered a result of verbal conditioning, so that even language expression could be described as observable behavioural output as a result of a complex sequence of inputs. Some ultimate consequences of this philosophy were that all behaviours are manipulable and hence in Skinner's overarching philosophy of man, we can assume that genetics would not have been considered to play a strong role in the explanation of behaviour. When processes within the black box were considered, or more concretely said, when thought or consciousness was no longer denied to exist, Experimental Psychology became the more general term for the science of describing quantifiable observed behaviours as functions of quantifiable sensory inputs in which intermediate stages, such as 'an internal representation or memory of a stimulus' which were in itself not directly observable by quantified methods, also played a prominent role. The contribution of behaviourism to modern human experimental psychopharmacology consists of the application of systems theory (black box approach) to human psychopharmacological observations. There is still a big gap between the known cellular effects of drugs and their observed effects on behaviour. Description of behavioural or performance effects of drugs as a mathematical function of exposure levels is a way to describe brain functions according to a black box approach that although different in nature, still very much resembles the methods of behaviourism to describe changes in overt behaviour as a function of changes in input (drug administration versus placebo). Furthermore, the attribution of behavioural effects of drugs to peripheral and not central levels of drug exposure is largely brought about by the difficulty to measure levels of drug exposure at the target organ, i.e. the brain (or specific regions therein). However this gap can nowadays be disclosed by PET ligand-binding studies to map the distribution of binding of drugs to a specific receptor. For example, changes in DA2-receptor binding correlate with changes in WM and planning, following dietary lowering of brain DA-levels [5]. The other difficulty consists of relating behavioural changes to neural substrate in between cellular neurochemistry and overt behaviour. That gap is now approached by combining overt behavioural observations such as quantified computerised performance measures with measures of inferred functional brain activity such as those provided by fMRI $[6,7]$. The combination of fMRI of cognitive functions and psychopharmacology is however, still in its early days.

\section{COGNITIVE PSYCHOLOGY: THE INFORMATION PROCESSING APPROACH}

Cognition is the label for all processes that mediate nonreflexive behaviour in living organisms. The central theme of cognitive psychology is that of the organism's internal representation of the outside world [8]. Behaviourism was at the root of experimental psychology, which could be described as the study of behaviours using formal logic and methods from natural sciences such as systems theory and mathematical modelling. The transition to Cognitive Psychology is manifested by the works of Newell \& Simon [9]. Their theoretical framework was information processing and attempted to explain all behaviour as a function of memory operations, control processes and rules. The methodology for testing the theory involved developing a computer simulation and then comparing the results of the simulation with human behaviour in a given task. Such comparisons also made use of protocol analysis in which the verbal reports of a person solving a task are used as indicators of cognitive processes and added the element of internal representation as central to the explanation of human information processing [10]. In order to perceive a stimulus correctly, an internal representation - implicitly referring to the concept of memory - is formed and used to compare the external stimulus to. The ideal result of this comparison is an adapted response. The comparator however, is biased and subject to base rates of limited sets of perceptions and responses. This principle can be applied in a behaviourist-like manner at a simple stimulus-response level to explain for example, a phenomenon like semantic priming: if a subject is shown a picture of a shoe and is subsequently asked the first other word that comes to mind, 'string' or 'foot' will be mentioned with a high frequency.

Another illustration is the building of expert systems and the explanation of expert knowledge. For example, novice and experienced clinicians differ in the way they perceive their patients and subsequently form their diagnosis. The explanation is not that their elementary perception is different, but their internal representation of the problem, to which their perception is compared, differs. Hence in experienced clinicians, just as in experienced chess players, and experienced painters, it can be shown that they use different search strategies when presented with a new problem situation, which is for example, manifested by different patterns of eye fixations, when they respectively inspect patient, checkerboard and painting. They are subject to the same perceptual laws, but actively search for different inputs. The cognitive explanation is that perceptual search, judgement, decision and overt response are governed by expectations, based on prior knowledge and experience [11]. Experience serves to build internal representations into coherent knowledge or expert systems which are called upon to decide what stimuli to search for and in which order.

Thus, an internal representation cannot exist without the concept of memory. Perceived images are stored in workingor short-term memory and compared with knowledge retrieved from long-term memory. Though memory is known to reside in the brain, it is certainly not one observable organ, but its vital functions, such as storage, search, consolidation and retrieval, can be assessed using neuropsychological tests, 
functional imaging, EEG measures, clinical ratings, or elaborate computerized methods. The vulnerability of memory is illustrated by the gradual, but in the end complete, disruption of this cognitive system in demented patients and it usually precedes age- and pathology related changes in performance on other cognitive tests. It is therefore rather logical that most trials on the efficacy of cognition enhancers primarily aim to assess improvements of memory functions.

Memory plays a central role in Newell \& Simon's [9] theory of human information processing. Their theory posits that humans can be represented as information processing systems which consist of an active processor, input (sensory) and output (motor) systems, and internal Long Term Memory (LTM) and Short Term Memory (STM), and External Memory (EM). How much processing such a system can accomplish per unit of time depends on the number of processes it can do simultaneously, the time it takes to do each process and the amount of work done by each individual process. Furthermore the system is serial, meaning that it can execute one elementary information process at a time [12].

The properties of LTM are: potentially infinite capacity, information units are symbols and relations among them, stimuli or patterns of stimuli called chunks become recognizable through learning, retrieval (read) time is milliseconds to one second (or not much more), storing (write) time is much higher (5-10 seconds per chunk).

The properties of STM are: small capacity, about 5-9 symbols, immediately and completely accessible, central gate in all information processing, subject to rapid decay unless rehearsed.

The properties of external memory are: the immediately available visual field, infinite capacity accessed by means ranging from linear scanning to random accessing, EM in this way can continuously refresh STM and hence can be used as an extension of it [12].

The now historic description above still rather directly implies which cognitive variables to measure in order to obtain a profile assessment of cognitive function:

- The number of simultaneous processes (selective attention and set shifting)

- The time it takes to do each process (Reaction Times)

- The amount of work done by each individual process (accuracies of responses)

- Retrieval and retrieval time of LTM (Recall and recognition from semantic memory)

- Storage and storage time into LTM (Recall and recognition from recent memory)

- STM capacity (memory span, e.g. digit span)

- Retrieval and retrieval time from STM (memory scanning time as in Sternberg task)

- Storage and storage time into STM (above as function of \# items memorised)

- Efficiency of EM (speed and accuracy of visual search)

The above can be considered as operationalisations of the concepts of Newell and Simon which defined basic elements of human cognition. This can be extended with other concepts such as distinguishing between implicit and explicit memories, sustained attention or vigilance and phasic and tonic motor readiness. The former and the latter are typical constituents of a cognitive test battery such as used in drug research of cognitive function [13-17]. In addition, executive functions are defined as the monitoring of one's own errors in difficult tasks such as selective attention (subdivided in focused and divided attention) and set shifting, strategy driven search in semantic memory (such as in verbal fluency tasks). In general, working memory tasks that require a combination of short term memory retention and updating (such as n-back tasks), are also considered an example of executive function tasks.

\section{PSYCHOPHARMACOLOGY OF ATTENTION AND COGNITION}

In their review of neuropsychological and psychophysiological mechanisms of attention, Pribram \& McGuinness [18] described three separate, but interacting, neural systems. One controls arousal, which is defined in terms of phasic physiological responses to sensory stimuli. According to Pribram and McGuinness the arousal control circuits center on the amygdala and are controlled by a serotonergic inhibitory, or 'stop' mechanism. A second system controls a 'go', or activation mechanism, which is defined in terms of tonic physiological readiness to respond. The readiness circuits centre on the basal ganglia of the forebrain. This second circuit is associated with noradrenergic (NE) pathways originating from the locus coeruleus and the primary dopaminergic (DA) pathway, which originates from the substantia nigra, innervating neostriatal structures of the basal ganglia (caudate nucleus and putamen) by way of the nigrostriatal pathway [19].

Whereas NE is associated with a reduction in motor activity, increased DA neurotransmission increases motor activity. The normal influence of DA on motor behaviour is excitatory, and results from an increased activity of the nigrostriatal and mesocortical systems. The primary effect on target neurons appears to be inhibitory, however. The effects of DA on target neurons are by no means direct, as it seems. Especially the interaction of DA with other transmitters present in the basal ganglia, such as acetylcholine and _-amino butyric acid (GABA) seems of importance. In contrast to the widespread activity of the NE system, the DA system is much more concentrated on specific structures, and its effect is the result of interactions with other transmitters rather than direct. DA modulates the glutamatergic corticostriatal transmission, although it is not yet clear whether the modulatory effect is excitatory or inhibitory or both [20]. The efferent projections from the striatum regulate the function of the globus pallidus (external segment), which in turn exerts an inhibitory control over thalamic motor centers.

Although the DA systems target motor functions, and do not appear to play a major role in sensory processes (as does $\mathrm{NE}$ ), they do appear important in co-ordinating motor output with sensory input. This is probably achieved by reciprocal innervation with thalamocortical centers. The result is an active, vigilant attentional mode, related most closely to motor readiness to respond. The DA system probably facili- 
tates the selection of specific motor acts and determines the sequence in which they are to be performed. Thus, the DA system is best described as a function of regulating the level of control over motor behaviour. Rather than simply increasing motor activity diffusely, it is the organisation of motor behaviour that is modulated. Tight control is exerted through high levels of DA functioning, whereas lower levels may result in less stringently controlled behaviour [21]. This theory has recently been reformulated to take account of allelic variability in the catechol-o-methyltransferase gene, which may confer more subtle variations in DA levels compared with the doses of amphetamine used in earlier studies [22].

A third system is discerned which coordinates arousal and activation. This coordinating activity is defined as demanding effort. Its circuitry centres on the hippocampus [18].

All three systems are controlled by ascending neurons originating from the reticular formation in the brain stem, but projecting to the different areas mentioned above. The term effort is chosen to reflect the fact, that the activity of the effort mechanism controls both the somatomotor system which initiates responses, as well as feedback from overt behavioural activity. Uncoupling the stimulus from the response, such as in response inhibition paradigms, demands changes in the central representation of the environment, a process that entails effort.

Animal behavioural studies suggest that the coeruleocortical noradrenergic system, under certain circumstances, is implicated in processes of selective attention, and that the mesolimbic and mesostriatal dopaminergic systems contribute to different forms of behavioural activation, and that the cortical cholinergic projections have fundamental roles in the cortical processing of signals, affecting attentional and mnemonic processes. As suggested by Pribram and McGuiness [18] the ascending serotonergic systems may contribute to behavioural inhibition and, indeed, appear to oppose the functions of the other systems in several ways $[19,23]$.

The neuroanatomy of attentional systems as described by Robbins \& Everitt [19] can be considered as a further elaboration of those described by Pribram \& McGuinness [18]. The classification of attentional functions, i.e. arousal, activation, effort and behavioural inhibition in terms of the modulatory effects of noradrenergic, dopaminergic, cholinergic and serotonergic neurotransmitters systems within their major projection targets, rather than their classification in terms of regional brain anatomy as in classical neuropsychology, provides strong clues for the prediction of drug effects on human behaviour [24].

\section{MODELS UNDERLYING TAXONOMIES OF COGNI- TIVE PERFORMANCE TESTS}

A thorough review, particularly in the context of using performance tests to assess effects of drugs, is presented by Wetherell and is highly recommended to the reader who wants to go in depth on these issues [25]. In brief, the article describes characteristics of tests, quotes about a 100 different examples of them and for a taxonomy of cognitive tasks re- fers at large to three models of human performance that predominantly explain the concepts behind cognitive tests. These are 1) the linear stage model 2) multiple resource/ resource strategy; and 3) factor analysis.

\section{THE LINEAR STAGE COGNITIVE ENERGETIC MODEL OF INFORMATION PROCESSING}

The identification of neural circuits involved in arousal, activation and effort have influenced research in both cognitive psychology and psychopharmacology [18, 23]. Sanders proposed that arousal, activation and effort act as three independent energetical supply systems that selectively relate to specific cognitive processing mechanisms [26]. These cognitive processing mechanisms act as more or less separate units in a linear stage structure of information processing from stimulus to response. Stress, or limited capacity, was defined as a state of imbalance in the energetic supply that is difficult to restore or to compensate [26].

One of the many implications of the linear stage model and its energetic supply systems is that the effects of psychoactive substances can be described in terms of their action on separate aspects (stages) of human information processing. A classical example of that approach is the finding that barbiturates degrade the arousal level because they interact with task factors that selectively determine perceptual processes, whilst an amphetamine-like substance stimulates the activation level because it interacts with task factors that selectively determine response preparation processes [27]. In the same manner, many drugs selectively acting on the noradrenergic, cholinergic and dopaminergic neurotransmitter systems have been applied as tools to study the pharmacology of human attention and information processing [2830]. By and large they report the associations of noradrenergic drugs with input or perceptual systems versus that of dopaminergic drugs with output or response systems, whereas cholinergic drugs interfere with the intermediate stages related to working memory or effort, although such distinctions are by no means absolute [23]. However, both the noradrenergic and cholinergic functions are associated with the ability to boost signal to noise ratio in the perception and processing of sensory information and both the cholinergic and dopaminergic systems are associated with working memory executive functions [23]. Recent work shows that DA has a critical role in working memory and also suggests a role for Ach in coding uncertainty associated with taskrelated contextual information [31].

The linear stage model is presented here as one that particularly provides guidance for predictions of drug effects. It should be mentioned however, that alternative models of information processing exist, such as cascade models that do not assume seriality of all stages of information processing, but assume continuous parallel processing in multiple nodes instead. The stroop-test is presented as an example where responding may occur before encoding has finished, which would explain the typical errors seen in this test and the difficulty of this test in general [33]. The linear stage model has been adopted to incorporate and limit the consequences of these apparent alternative explanations. For example, if a drug affects performance on the Stroop test, the explanation would be to assume that the drug effect would be on the ex- 


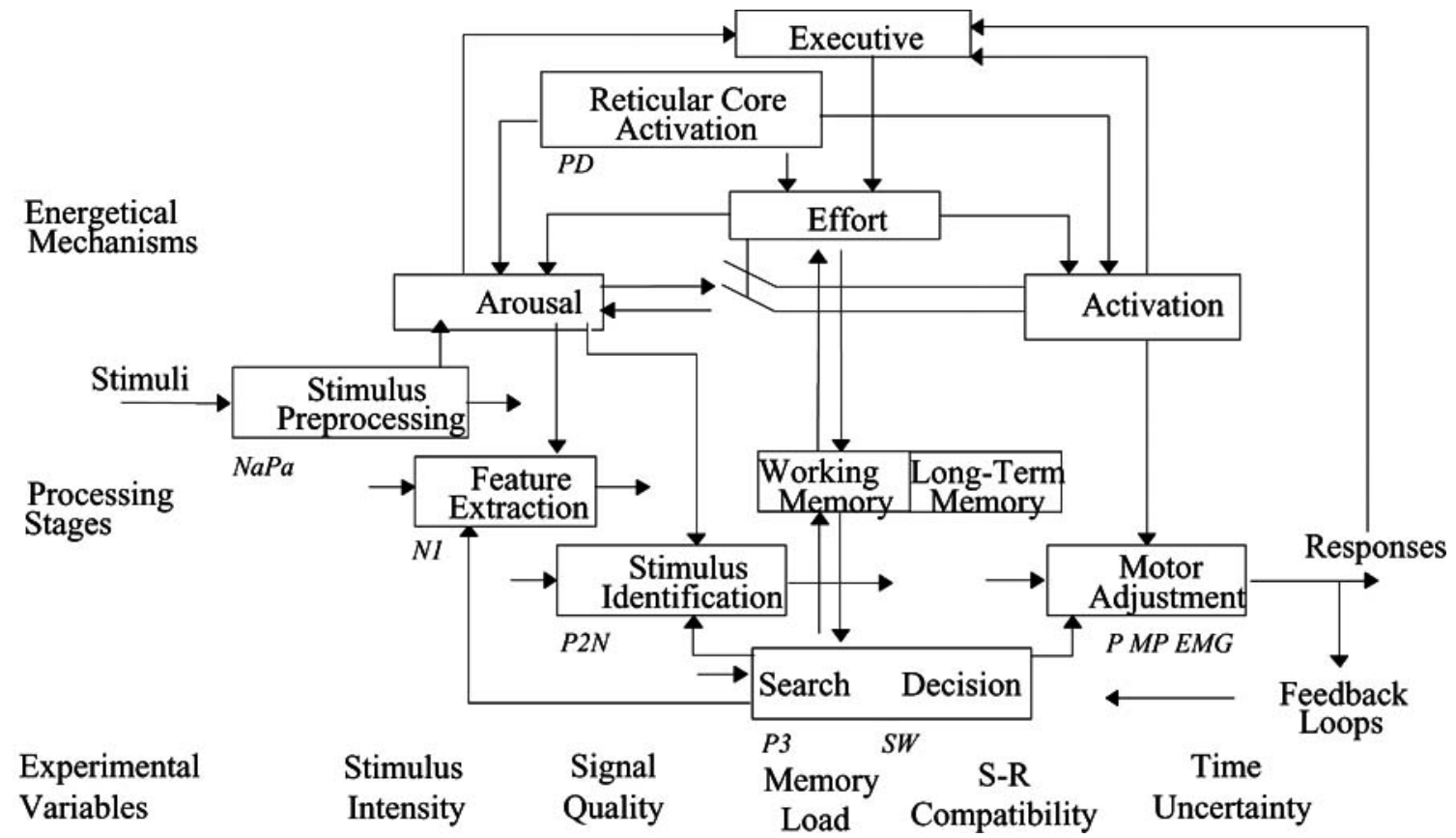

Fig. (1). The Mulder-Sanders Linear-Stage Cognitive-Energetic Model of Information Processing (after [26, 32, 34]). Experimental variables (such as Stimulus Intensity) specifically affect individual stages of cognitive processing. Physiological markers of specific cognitive processes are indicated in the model: NaPa, N1, P2N2, P3 = Evoked Response Potentials; PD = pupil dilation; SW = subjective workload; BP = bereitschaftspotential; $\mathrm{MP}=$ Motor Potential; $\mathrm{EMG}=$ electromyogram. (Revelle W. Individual differences in personality and motivation; 'non-cognitive' determinants of cognitive performance. In A. Baddeley \& L. Weiskrantz Eds., Attention, Selection, Awareness and Control. Oxford: Clarendon Press. 1993).

ecutive mediating inhibitory control. According to Sanders, errors on the Stroop test are explained by an immediate feedforward from arousal to activation, hence skipping the decision stage. To prevent these errors from occurring, response inhibition and self-monitoring of errors is necessary to occur under the control of the executive processor [26].

\section{RESOURCE MODELS OF INFORMATION PRO- CESSING}

The resources approach is based on the notion of availability of scarce processing resources and the economy according to which these resources are allocated to information processing tasks or subtasks. A distinction can be made between single and multiple resource models $[35,36]$.

The simplest resource model assumes one single pool of resources, to be termed "processing capacity", "attention", or "effort", which is controlled by feedback. When an ongoing task requires an increased amount of capacity in order to process the present information, there is an increase of arousal, and with this, an increase in attention. The total amount of supplied resources varies with physiological arousal and is controlled by the demands. The amount of effort invested in a task is not subject to voluntary control, even if the allocated resources do not always yield perfect performance. The level of physiological arousal can be indicated by pupillary dilation, skin conductance measures and heart rate, among others [35].

The most important implication from this notion is that the effects of a drug may not manifest in changes in test performance due to the fact that more effort and hence more processing resources has been invested in the test. Most typically then the effect of the drug is manifested through a subjective feeling of subjects or patients that in order to achieve the same level of performance, much more attention/effort has been invested in a task. An example of this is that it may cost the subject more difficulty to stay awake as a result of a sedating drug. The pattern of results after a sedative drug thus would be: equal performance relative to placebo and an increased subjective feeling of effort. Physiological signs of arousal, effort or activation may be difficult to disentangle because a mixture of drug-induced influences (bottom-up) and compensatory effort-induced influences (top-down) on physiological signs may occur. However, the concept may also be used to explain the difficulty in enhancing cognition drugs in healthy volunteers who may be performing optimally under placebo conditions. However, the drug may enhance efficiency of some functions, reducing subjective effort to perform cognitive tasks at the same level [37]. In that case cognition enhancement does not manifest as improvement of cognitive performance, but as decreased effort needed to achieve the same optimal performance. Physiological measures may reflect direct drug-induced signs of tonic activation such as increased heart rate and blood pressure. Since not all tasks are performed optimally in all situations [38], there is also the potential to improve performance in line with reduced effort, or increased efficiency of taskrelated processes as demonstrated with methylphenidate [39].

The multiple resource model assumes that an interference of performing one task while simultaneously performing a second task is given under the condition of resource compe- 
tition [36]. This can occur at the level of processing stage: when two tasks require different types of processing they draw on separate resources, such as in listening (sensory) while driving (motor). When capacity has to be shared between two tasks involving two different sensory modalities (in particular auditory vs. visual), the better performance is achieved when the modalities are different than when they are the same. Spatial and verbal codes are differentially represented in neuropsychological models of working memory, with suggestions that processing of spatial codes involves right-lateralised networks, whereas the left-lateralised networks are more commonly seen with verbal coding. These concepts should be taken into account when designing socalled attention-dividing, concept-shifting or dual tasks. The digit-symbol substitution test is an example of a test that requires many different psychomotor and cognitive functions at the same time: a) perceptual encoding of symbols; b) the storage of symbols or symbol-digit relations in working memory; c) the central process of translating symbols into digits; d) the selective or focused attention to a position on the sheet while ignoring symbols in other positions; e) dividing or shifting attention from symbols to digits; f) the control of eye movements back and forth across the sheet; g) the skill of writing down the digits; h) monitoring of one's own tendency to make errors i) the subjects motivation, because the task is self-paced and therefore vulnerable to lapses of attention [15]. Probably the well-known high drugsensitivity of this task is due to the fact that it draws on many different resources and therefore does not allow for a compensation strategy by means of investing more effort in the test to keep performance at a constant level. In general, the relevance of the notion of multiple resource pools $v s$. a single resource pool is that in several cases the concept of a single resource pool, hence a single dimension of arousal that underlies alertness, is too simple. A cognition enhancing drug could be specifically improving perception or alternatively could be specifically enhancing response readiness, rather than unidimensionally improving everything such as predicted by the single resource model. Reciprocally a cognition impairing drug could be specifically impairing specific aspects of cognitive performance rather than a global impairment, which would be expected for a generally sedating drug [40]. For example note that this discussion bears a high degree of relevance for designing the 'non-sedating anxiolytic'.

\section{HOW MANY COGNITIVE DOMAINS? ANSWERS FROM FACTOR ANALYSES}

Wetherell describes two different approaches to factor analyses. [25] The first assumes that one to several independent factors describing cognitive abilities exist in nature and tests will uncover them. The second merely uses factor analysis of an array of performance variables to summarise data and reduce the often large set of measures to a small set of independent factors. A range of outcomes have been considered, the highest estimate of independent cognitive functions being 37, the lowest resulting from the assumption that one general factor explains all. However, most authors conclude that about 4 or 5 independent factors are needed to explain variation in cognitive performance data, brought about by the effects of drugs. We consider two of these in particular, CANTAB (CAmbridge Neuropsychological Test Automated Battery) and CDR (Cognitive Drug Research), because they are often encountered in psychopharmacological research and because the relevant factor analyses of their data structure have been published in the literature [17, 4143].

A factor analysis on 11 variables of the CANTAB battery consisting of learning, memory and visual search tests taken in a sample of $\mathrm{N}=787$ from an elderly population (55-80yrs) revealed that $60 \%$ of the variance could be explained by 4 factors which were described as 1) learning and memory; 2) speed of responding; 3) executive function including spatial working memory; and 4) visual perceptual ability [41].

In a subsequent study, in a sample of $\mathrm{N}=215$ from a healthy young to elderly population (21-79yrs), using a larger battery of tests, especially in the executive function domain, similar results were obtained, although the order of factors had changed and two significant additional factors, the first of which was related to attentional set shifting and the second to spatial working memory, were reported [42].

A factor analysis on 16 cognitive performance measures from the 'CDR-battery', another frequently used test battery in human psychopharmacology, yielded 5 factors described as speed of memory, quality of episodic secondary memory, speed of attention, quality of attention and quality of working memory [43].

One conclusion that may be drawn from Table $\mathbf{1}$ is that overall, any cognition test battery will yield about a handful of essentially different factors, although this will necessary be dependent upon the actual variety of measures recorded. In the examples chosen, the factors that were derived at first glance may differ somewhat. Common elements are memory factors represented by factor 1 in CANTAB and Factor 2 in CDR. Factor 2 and perhaps 6 in CANTAB seem to correspond to factor 5 in CDR. Factor 3 in CANTAB seems to correspond to factors 1 and 3 in CDR. Finally, factors 4 and 5 from CANTAB do not seem to correspond on a conceptual level with factor 4 from CDR, although one could argue that there is a weak correspondence between both factors 4 , but the variables that load on the CDR factor 4 represent easier test measures than those represented by the CANTAB factor 4 which seem to represent higher cognitive functions.

\section{PROCESS- $V S$. PRODUCT-APPROACH: MULTIPLE FACTORS, ONE TASK VS. MULTIPLE TASKS, ONE FACTOR}

Gaillard [15] described the dilemma of either using a test battery (multiple tasks one-factor) or a one-task multi-factor approach to assess effects of drugs on cognitive performance and concludes to opt for a compromise of both.

In psychodiagnostic research, tests are applied to evaluate the performance of individuals and to compare performance between individuals. In experimental psychological research performance tasks are applied to study psychological processes and hence to compare between conditions, often within individuals. Performance testing in CNS drug research, however, is primarily applied to evaluate the behavioural effects of drugs [14] and secondarily, is used in some cases to study reactions of individuals or selected groups such as in pharmacological challenge tests [16]. 
Table 1. Results of Factor Analyses of Test Variables from the CANTAB Test Battery [42] and the CDR Battery [43]

\begin{tabular}{|c|c|}
\hline CANTAB Factors & CDR Factors \\
\hline $\begin{array}{l}\text { 1. Visual Memory Encoding and Learning } \\
\text { Paired Associate Learning Number of Trials } \\
\text { Paired Associate Learning Memory score } \\
\text { DMTS (del) accuracy } \\
\text { Pattern Recognition accuracy } \\
\text { DMTS (sim) accuracy } \\
\text { MTS (visual search) accuracy }\end{array}$ & $\begin{array}{l}\text { 1. Speed of memory processes } \\
\text { Picture Recognition RT } \\
\text { Word Recognition RT } \\
\text { Numeric Working Memory RT } \\
\text { Spatial Working Memory RT }\end{array}$ \\
\hline $\begin{array}{l}\text { 2. executive function / spatial working memory } \\
\text { Spatial Working Memory Between-search errors } \\
\text { Tower of London Initial movement time } \\
\text { Spatial Working Memory Strategy score } \\
\text { Spatial Span } \\
\text { Tower of London Subsequent movement time } \\
\text { Spatial Recognition }\end{array}$ & $\begin{array}{l}\text { 2. Quality of episodic secondary memory } \\
\text { Immediate word recall accuracy } \\
\text { Delayed word recall accuracy } \\
\text { Word Recognition Accuracy } \\
\text { Picture Recognition Accuracy }\end{array}$ \\
\hline $\begin{array}{l}\text { 3. speed of responding } \\
\text { MTS (visual search) latency } \\
\text { DMTS latency }\end{array}$ & $\begin{array}{l}\text { 3. Power (speed) of attention } \\
\text { Simple Reaction Time } \\
\text { Choice Reaction Time } \\
\text { Digit Vigilance Detection RT }\end{array}$ \\
\hline $\begin{array}{l}\text { 4. Executive and planning functions } \\
\text { Tower of London Subsequent thinking time } \\
\text { Tower of London Initial thinking time } \\
\text { Tower of London Minimum moves }\end{array}$ & $\begin{array}{l}\text { 4. Continuity (accuracy) of attention } \\
\text { Digit Vigilance Detection Accuracy } \\
\text { Choice Reaction Time Accuracy } \\
\text { Digit Vigilance False Alarms } \\
\text { Tracking Error }\end{array}$ \\
\hline $\begin{array}{l}\text { 5. Attentional set shifting } \\
\text { Attentional Shift Total errors (ED stage errors) } \\
\text { Attentional Shift ED errors }\end{array}$ & $\begin{array}{l}\text { 5. Quality of working memory } \\
\text { Numeric Working Memory Accuracy } \\
\text { Spatial Working Memory Accuracy }\end{array}$ \\
\hline $\begin{array}{l}\text { 6. Spatial Memory } \\
\text { Spatial Working Memory Within-search errors }\end{array}$ & \\
\hline
\end{tabular}

RT, Reaction Time; DMTS, delayed matching to sample; del, delay trials; sim, simultaneous condition trials; MTS, matching to sample; ED, extra-dimensional shift.

The effects of drugs are often measured with a multitude of different tasks, primarily to establish whether there is a drug effect at all and if so, whether the drug effect is general or specific. The advantage of this approach is obvious in that it is based on covering a profile of cognitive functions as complete as possible. However, the disadvantage is the lack of sensitivity of such a procedure if a drug effect is highly specific and this was not specifically hypothesised (which is nearly always true). Say, drug $X$ affects only cognitive function $\mathrm{Y}$ which is 1 of 10 different cognitive functions. In that case a statistical problem emerges; because the falsification of the null-hypothesis that drug $\mathrm{X}$ is ineffective is tested 10 times, the specific effect of drug $\mathrm{X}$ on $\mathrm{Y}$ needs to pass a significance level that is corrected for multiple testing. Such an approach is therefore insensitive to detect specifically targeted drug effects, although it may be useful more generally in hypothesis generation.

Another approach is the 'one test with many task factor manipulations'-approach. This consists of using only one paradigm, for example the presentation of 1 or more letters on a computer screen for a brief amount of time, with a varying set of instructions such as whether that letter is part of a set of targets that was viewed a few moments earlier (the Sternberg paradigm) [44]. In such a case the responses will be analysed as a function of the number of target-letters 'held' in working memory and subsequently how drug exposure affects that relation. In this case there is each time only one dependent variable such as Reaction Time (assuming that accuracy is always $>90 \%$ and we can ignore effects on response accuracy). The effects of drugs will manifest as the statistical interaction (in an analysis of variance design) of the factors 'memory load' and 'drug exposure' (one or more doses of drugs vs. placebo). The primary advantage of such a design are that they are more process-specific (if the 'drug * task' interaction is found, we can be certain that there is an effect on working memory - if it is not found, this strongly suggests that drug $\mathrm{X}$ does not affect working memory as tested by the Sternberg task). Ideally, with the same task we can manipulate other factors to address the same question: e.g. by varying stimulus quality we can test if the drug affects perceptual encoding; by varying the interstimulus interval duration, we can test if the drug affects motor readiness and by varying the complexity of the response we can test 
maintenance versus manipulation of information held in working memory. All this can be achieved using the same letter detection task.

One obvious disadvantage of this procedure is the emergent monotony because all the tasks follow more or less the same regimen, which decreases the attractiveness of being tested and therefore might unfavourably influence motivation of subjects or patients.

One other issue to consider when choosing an approach is how many independent cognitive functions do exist? Using a test battery with 10 tests suggests that one has assumed that 10 independent cognitive functions exist, or at least warrant testing. Similarly, in the model of stages of information processing the number of boxes in between stimulus and response reflect the number of independent stages of information processing. A quick browse through the literature around these models suggests that most of them show 3 or 4 stages, whereas at some time as much as 7 independent serial stages of human information processing have been suggested [45]. It would be impractical to experimentally test the effect of drug $\mathrm{X}$ on all these stages at once.

\section{SCIENTIFIC IMPLEMENTATION: VALIDITY AND RELIABILITY}

Parrott outlined the requirements for performance tests in human psychopharmacology: reliability and standardisation [46], content validity, criterion validity and face validity [47], construct validity and test implementation [48]. Sensitivity to psychoactive drug effect is also an important prerequisite for tests in this area, although traditionally it is not in itself considered as an index of validity.

For any single test or set of tests of cognition to develop for, or apply in drug development, this means that the following needs to be known:

- Reliability:

- Standardisation:

- Criterion validity:

- Content validity:

- Face validity:

- Drug Sensitivity:

- Construct validity:

- Test interpretation:

Test-retest reliability correlation, internal reliability

Documentation

Correlation with external criterion (target behaviour)

Appropriateness of test selection

Important for motivation of subjects, but caution warranted

Evidence of this is required

Test supports underlying model or theory

Results must be easy to translate / generalize

Additional often recurring issues are test specificity (or concurrent validity) and practice effects, which both pertain to drug sensitivity. Technical issues are pencil-and-paper testing vs. computerised testing and in the latter case what are the minimal specifications for computerised testing and in particular the necessity to use peripheral response devices.

Most researchers agree that days of pencil and paper testing are over, because it has been shown many times that automation of cognitive testing procedures increases reliability and drug sensitivity relative to non-automated penciland-paper procedures [17]. Most clearly, in addition to double-blinding, automation largely eliminates investigator bias in their relation with subject or patient thereby decreasing error variance in outcome measures [49].

The importance of practice effects can not be understated, because they are probably determining placebo response to a considerable degree. This is particularly the case in drug trials in cognitive aging and dementia where practice of the primary outcome instrument is not standard, for example in Alzheimer's Dementia drug trials the ADAS-Cog is never practiced. Studies into learning or practice effects with the ADAS-Cog have clearly pointed out that these effects do exist during the first 16 weeks of treatment [50]. Another recent example is the PROSPER study, a large treatment evaluation study of cholesterol lowering agents' effects on cognition, which suffered from practice effects obscuring a possible treatment effect [51]. There are several types of practice effects, the most obvious ones, learning the stimulus items in memory tests for example, can be prevented by the use of parallel versions of the tests. However, learning to understand what is required in the test and learning to anticipate what comes when, also called procedural learning as well as anxiety reduction or habituation to the test environment, may greatly contribute to practice effects. A proper familiarisation program to rule out these effects and potentially enhance the drug sensitivity would work irrespective of the computerised or pencil-and-paper format of the tests. However, the problem is more often associated with penciland-paper tests, because it reflects the tradition in clinical psychology that psychological assessment is a one-off event [51].

None of these issues are absolute. However, it is often argued that elderly, especially dementia patients are less suitable for computerized testing because they have rarely been familiarized to computers. Besides the fact this argument will completely lose validity in another $20-40$ years, it should be taken as a challenge for neuropsychologists to collaborate with the best and most creative software designers rather than as an argument to choose the easy way out and keep with the status quo. Nevertheless all should be held against the light of required precision: a non-subtle drug effect will also be detected by non-subtle pencil-and-paper tests. However, development economics have it that we would like to see the non-subtle drug effects earlier: i.e. when they are still subtle and therefore we do need more precise instruments.

\section{COGNITION DISEASE TARGETS FOR DRUG DEVELOPMENT}

In the foregoing, cognition has been largely implicitly defined as those functions that are optimal in young adulthood and which usually decline in aging and similarly are subject to pathological decline in dementia. Therefore, with respect to the foregoing, methodology has been the focus but mild cognitive impairment and dementia have been the implicit targets for drug development. However, there are other cognition targets for drug development as well, in particular schizophrenia. Furthermore psychometric assessments to 
detect cognition enhancing effects are of relevance in drug development for ADHD, depression and anxiety. The opposite, to assess the absence of cognition impairing effects has a short history in clinical neuropsychology, [52] but a much longer history in human psychopharmacology [53]. The reader is referred to reviews of antidepressant- [54], antipsychotic- [55, 56], anxiolytic- [57], hypnotic- [58] and antihistamine effects on cognition and psychomotor performance [59]. The issues of psychometric assessment discussed in this article also apply in this area of research [4648].

\section{CONCENSUS ON COGNITIVE DOMAINS FOR SCHIZOPHRENIA: THE MATRICS INITIATIVE}

A recent development is the "Measurement And Treatment Research to Improve Cognition in Schizophrenia" (MATRICS) established by the National Institute of Mental Health (NIMH) to stimulate the development of new drugs for the cognitive deficits of schizophrenia [60-65]. The MATRICS committee identified the cognitive domains that should be represented in a consensus cognitive battery for assessment of antipsychotic drug effects. Seven cognitive domains were selected based on a review of the literature and input from experts:

1. Working memory

2. Attention/vigilance

3. Verbal learning and memory

4. Visual learning and memory

5. Reasoning and problem solving

6. Speed of processing

7. Social Cognition

Furthermore, five criteria were considered essential for test selection:

1. Good test-retest reliability

2. High utility as a repeated measure

3. Relationship to functional outcome (same as criterion validity)

4. Potential response to pharmacologic agents

5. Practicality/tolerability and Sensitivity for practice or learning effects

As can be seen, the MATRICS approach reflects the general message in this article. One can argue over the number of domains and whether all domains are comparable and necessary in terms of fulfilling the criteria for test selection. For example there is abundant evidence that working memory as a domain is highly sensitive to psychoactive drug effects, but such has never been demonstrated for social cognition. Conversely, working memory and learning are likely to be sensitive domains, but not very specific for schizophrenia. Memory performance tests are also a relevant domain in aging, dementia, ADHD, depression, anxiety and sleep disorders and consequently a memory test will be a sensitive marker of any CNS drug effect. Social Cognition may be of diagnostic relevance, but the problem is that just as is the case for executive cognitive functions such as reasoning and problem solving, these concepts have hardly ever been translated into tests with a high reliability because they are by definition, sensitive to change of strategy, which is in turn what these tests are supposed to measure [66].

As Lowe and Rabbitt [66] point out, "A possible explanation for differences in test-retest reliability might be that tests of frontal or 'executive' function 'work' only when they are novel because performance on them can abruptly improve as soon as an individual discovers an optimal strategy, but will improve less, or not at all if no strategy is found and may even deteriorate if a suboptimal strategy is attempted. Practice effects will, therefore, markedly differ between individuals and for this reason test-retest reliability will be low. In contrast tests in which improvements with practice are gradual because sudden, strategy-driven improvements in task strategy are not possible will be much more robustly reliable."

\section{BIOMARKERS OF COGNITION}

The ideal measure of a cognitive process would be a manifestation of the process under study, rather than a correlate of that process $[67,68]$. According to the linear stage model of information processing, cognitive mechanisms are of differing timescale. The arousal mechanism typically elicits transient changes in brain activity as well as in the cardiovascular system. The activation mechanism, on the other hand, usually extends over a longer period of time, albeit that the physiological correlates - especially those that reflect the activity of the sympathetic nervous system - can often only be distinguished from those elicited by the arousal system on the basis of just that time scale. It would therefore be of use, to find those physiological parameters that are exclusively indicative of the activity of either arousal or activation or effort. Unfortunately, such parameters are not readily available. Since each of the mechanisms expresses itself by means of the autonomic nervous system, measurements of parameters reflecting the activity of the autonomic nervous system may in fact reflect the additive effects of several mechanisms, including those that are elicited without interference of the central nervous system. The criteria for these parameters include sensitivity, diagnostic specificity, intrusiveness, reliability and generality of application.

\section{CORTICAL MARKERS}

Recordings of electrical and magnetic brain activity from the skull, is a method widely in use for the study of cognitive processes. Two general techniques are widely used: the measurement of overall electrical activity of the central nervous system, and the measurement of event related potentials.

\section{Electroencephalographic Activity}

The measurement of EEG activity can be used to register both tonic and phasic aspects of the continuous spontaneous activity of the CNS. The most general change in EEG as a result of cognitive workload can be found in the alpha band $(8-13 \mathrm{~Hz})$ : alpha band power is inversely related to cognitive task difficulty. Power is reflected by the total area under the curve within a defined frequency within a defined amount of time. Under most circumstances it is possible to observe a 
shift from alpha rhythm to beta rhythm $(14-20 \mathrm{~Hz})$ whenever concrete cognitive demands are present. In addition, activity in theta band may be reduced. Preparation for action can be observed as a gradually developing negative variation of electrocortical activity: the contingent negative variation (CNV). Its late component is considered to be indicative for the level of motor preparation. EEG metrics (alpha and theta bands) may provide sensitive indices for overall levels of arousal and alertness, but they are not selectively sensitive to different varieties of cognitive processing demands [69]. The use of EEG recordings implies the absence of overt behaviour. Where this can be taken for granted, the alpha power metric is relatively reliable as a measure of the general level of alertness. Its generality is limited, though, since an array of sources (EOG, ECG, 50/60 Hz net power frequency) may contaminate the signal.

\section{Event Related Potentials}

The timing of computational cognitive mechanisms is assumed to be indicated by the latency of components in the brain evoked potentials. Thus, stimulus pre-processing is indicated by the $\mathrm{N}_{\mathrm{a}}$ and $\mathrm{P}_{\mathrm{a}}$ components, feature extraction is indicated by the $\mathrm{N} 1$, the $\mathrm{P}_{2} \mathrm{~N}_{2}$ complex (including "mismatch negativity"), indicates the stimulus identification stage, and controlled processing is typically indexed by the $\mathrm{P}_{300}$ latency and amplitude. The $\mathrm{P}_{300}$ component, characterized by its latency of typically around $300 \mathrm{~ms}$, seems to be associated with the moment at which a decision or classification takes place. Thus, the latency of the $\mathrm{P}_{300}$ reflects the time needed to complete all computational mechanisms up to the comparison stage. By this, the P3 latency and amplitude are an excellent indicator of processing complexity effort. Similar to EEG recordings, the ERP metric is easily intruded by artefacts, especially those related to eye movements.

\section{FUNCTIONAL MAGNETIC RESONANCE IMAGING AND POSITRON EMISSION TOMOGRAPHY}

The use of functional magnetic resonance imaging (fMRI) and positron emission tomography (PET) to assess the effects of pharmacological agents allows measurement of whole-brain changes with a spatial resolution in the order of $\mathrm{mm}$ and temporal resolution of seconds (fMRI) and minutes to hours (PET). PET methods allow the quantitative measurement of regional cerebral blood flow (rCBF) and metabolism, as well as the direct central effects of pharmacological challenges. Thus, using PET not only allows measurement of the effects of challenges on brain 'activity' per se, but also allows relating of overt cognitive and behavioural changes to exposure of the target brain structures to the effects of a challenge $[5,70]$. These techniques have yet to be used to define the cognitive and behavioural effects of variable central nervous system exposure to psychopharmaceuticals.

Although in its infancy, combinations of psychopharmacology with fMRI have been more widely employed to date $[71,72]$. The main measure used, the blood oxygen level dependent (BOLD) effect, indexes the relative amount of deoxygenated haemoglobin in the cerebral vasculature, which is paradoxically decreased in active brain areas due to blood flow increasing more than the expected rise in oxygen demand. The principle challenge for pharmacological studies is in delineating the fundamental processes by which drugs alter fMRI signals, which include direct effects upon cerebral vasculature, as well as effects upon neural activity and potential alterations in neurovascular coupling. In taskmodulation studies, the use of carefully designed control comparison tasks minimises the non-specific effects of drug that are measured. More recently, evidence from combining fMRI with event-related potentials has demonstrated that the dopamine D2 receptor antagonist has a similar effect on the power law relationship between the intensity of somatosensory stimulation and both electrophysiological and fMRI measures of cortical response [73]. Similar combinations of fMRI measures with electrophysiology, quantitative measures of blood flow and metabolism, and cognitive changes will be important in future studies.

\section{PUPIL DIAMETER}

The size of the human pupil is controlled by the cooperative function of two muscles, and may vary from 2 to 8 $\mathrm{mm}$. Apart from responding to changes in the amount of light falling upon the eye, a number of other factors (near vision, lid closure, pupillary unrest) play a role in the dynamics of pupil diameter. The phenomenon of pupil dilation as a response to cognitive workload is based upon the differential innervation of the dilator and the sphincter muscle. The relatively weak dilator muscle cannot be considered a real antagonist to the much stronger sphincter muscle [74]. Since only very few adrenergic synapses in the sphincter muscle have been found, it is generally assumed that pupil dilation in response to mental processes is essentially the result of central inhibition of the oculomotor nucleus. The dilator pupillae is innervated by a sympathetic nerve, whereas the $\mathrm{m}$. sphincter pupillae is under vagal control. Thus, changes in pupil size may be due to either sympathetic or parasympathetic influences, or any combination of both. Although the relationship between cognitive operations and pupil diameter has repeatedly been demonstrated, it is important to note that these effects are considerably smaller than pupillary changes due any of the other reflexes. The pupil diameter is a sensitive and reliable metric of acute cognitive capacity. Since it does not seem to discriminate between differing task situations, it is regarded as an indicator of reticular core activation.

\section{CARDIOVASCULAR MARKERS}

A number of cardiovascular parameters are controlled by the autonomic nervous system. An increase in parasympathetic tone is characterised by a decrease in heart rate (bradycardia), a lowering of blood pressure, and an increase of variability in heart rate (sinusarrhythmia). The parasympathetic effect is counterbalanced by the sympathetic branch of the autonomic nervous system: an increase in activity of the sympathetic nervous system results in an increase in heart rate (tachycardia), an increase in blood pressure, and a decrease of sinusarrhythmia. Activation of the cardiovascular system can be invoked through internal stressors such as (cognitive) memory load or external stressors such as environmental noise. Both may interact with pharmacological treatment. Activation through cognitive load is a function of the way in which subjects cope with the demands, whereas activation through external factors is a func- 
tion of the non-cognitive or emotional response to changes in task environment. The sensitivity of the cardiovascular system to changes in task demands is based upon the sympathetic and parasympathetic innervation of the heart, which is relayed by the baroreceptors in the aorta and carotid arteries [75].

\section{Heart Rate and Heart Rate Variability}

Tonic heart rate has repeatedly been shown to increase under high mental load $[76,77]$. Since the heart rate metric is easy to obtain, it has been used in numerous studies indicating a relationship between heart rate and mental workload. Despite this, there is no unanimity as to what change in heart rate is the result of what change in workload. For relatively low workload in low stress simulated flight (e.g.), heart rate reflects variations in physical control demand but not cognitive load levels [78]. Compared with a control condition, heart rate increases when a mental arithmetic task is performed [79]. The biological relevance of the increase in tonic heart rate has been the subject of some debate. One reason is certainly, that a redistribution of blood supply can make up for the increased oxygen consumption by the brain [80], although Jennings argues that the cardiovascular response to information processing demands per se is not a passive response to increased metabolic demands [81].

A different way of looking at tonic heart rate is by treating the continuous recordings of the interbeat intervals as a time series. On the basis of an analysis of the frequencies constituting the series (Fourier analysis), a number of periodic changes in heart rate can be discovered. A spectral analysis of these frequencies reveals three major components:

A low band of frequencies ranging from 0 to $0.06 \mathrm{~Hz}$ is associated primarily with vasomotor activity in response to the regulation of body temperature

A medium range from 0.06 to $0.14 \mathrm{~Hz}$ is associated with the response to baroreceptor activity due to fluctuations in arterial blood pressure, and a high range, between 0.15 and $0.5 \mathrm{~Hz}$, which is a response to respiratory activity.

Under high mental load, frequencies around $0.10 \mathrm{~Hz}$ tend to be of lesser amplitude, which means that among the total amount of variability in heart rate, less is attributable to responses to arterial blood pressure fluctuations. Rather than being the result of a decrease in fluctuations of blood pressure, it is considered to be resulting from a lowering of the baroreceptor sensitivity.

Over the past decades, heart rate variability has been studied under numerous circumstances, both in experimental and in applied settings. The most important observation is that HRV is negatively related to the amount of effort (controlled processing) invested in a task [82]. The energy in the mid-frequency band (around $0.1 \mathrm{~Hz}$ ) decreases as a function of the amount of effort invested. [83] In motor car drivers a decrease of spectral energy in the mid-frequency band was found to coincide with the distance driven [84]. Thus, the HRV seems to be a sensitive indicator of mental effort. However, there are a number of caveats to take into account. In the first place, despite increases in required mental effort, the HRV increases during speaking [83]. Another problem is the requirement of stationarity during the measurement period. The stationarity requirement states that the average heart rate during the measurement should remain constant.

\section{ENDOCRINE MARKERS}

Biochemical analysis, for example the analysis of catecholamine levels in blood plasma and urine, may help identifying the activity of the sympathetic nervous system. The levels do not only reflect mental effort, but also physical effort, however. The relative amount of noradrenaline is usually higher under physical load, whereas the relative adrenaline level is higher under mental load [85]. Lundberg \& Frankenhaeuser [86] found the metric to be especially sensitive for differences in effort invested in a mental arithmetic task performed under different levels of white noise. Thus, the NA/A ratio seems useful as an index of mental effort, in particular for compensatory effort. Fibiger \& Singer [87] report typical urinary NA/A ratios for physical "work" (boxing, icehockey) of well over 10, whereas the typical NA/A ratio for computerised administrative work is about 4.0, for vigilance tasks 3.77 and for examination stress 2.19 . The measurement of plasma concentrations even allows for the monitoring of transient changes, but this is not without difficulty. In particular, the invasive techniques necessary to perform the measurement may itself be of influence on the level of secretion of catecholamines.

A problem with urine level probes is that these measurements can only take place in relatively widely spaced time intervals, which implies that the introduction of new task conditions should be equally delayed, a procedure which is altogether less appropriate for the study of a reasonably large number of different task conditions. Furthermore, since the metric of NA/A ratio can only be used for the estimation of changes of endocrine function over relatively long periods of time, its use is restricted to the assessment of global changes in level of mental activity. Since excretion of adrenaline is subject to circadian influences, its reliability is strongly dependent upon the comparability between test and control sampling conditions.

Salivary cortisol levels have been reported to rise with psychological stress and mental effort [87]. Moreover, cortisol levels seem primarily indicative for emotional components of effort $[88,89]$. Cortisol excretion is subject to strong circadian influences, however, which implies that samples must always be compared with control sample from the same phase of the circadian rhythm. This may pose a problem, since it requires subjects not to be engaged in any relevant activity during and prior to taking the control sample. Considering the empirical results of measuring plasma and urinary levels of endocrine substrates, the metric seems to be sensitive to differences in compensatory effort. Whether it is selectively so, cannot as yet be decided on the basis of empirical data.

\section{RATIONALE AND GENERAL HYPOTHESES}

A rationale for cognition assessments or biomarkers of cognition as outcome measures in CNS drug development research is determined by various factors. Several hypotheses from the very general to the very specific can be identified. It is important to make a distinction between hypothe- 
ses that take the disease into account, for example by assuming impaired performance in the target population, and hypotheses that are solely based on drug action. Sometimes these cannot be separated because a drug effect is hypothesized only in the disease group. However, very often these assumptions are made without any basis in fact. For example, it is very often claimed that 1) anxiolytics should always be sedative, because that would actually neutralize the elevated physiological arousal which is associated with impaired baseline performance in anxiety patients. Ergo, 2) the problem of cognitive / psychomotor impairment would not count in patients because they will perform better rather than worse on tests that require alertness, attention and concentration. This hypothesis is very often encountered, not only in anxiety but also in other areas such as schizophrenia, but has hardly ever been investigated. While 1) may sometimes be true, 2) is not. In a comparison of two anxiolytic substances, the results clearly showed that untreated anxious patients did not perform any worse than controls on a driving test and that sedative effects of anxiolytics were just as detrimental to performance in anxious patients as in healthy controls [90, 91].

The first (but not necessarily the most frequent) hypothesis in drug development in humans is often evidence of brain penetration. Can we use cognitive or psychomotor tests or cognition biomarkers to demonstrate that? The direction of the change in this respect is unspecified: either a significant improvement or impairment will falsify the null-hypothesis of no change. In this case the dilemma between choosing a number of tests or one single test is clear: if more variables are chosen to analyze, then the design will become less sensitive, because of correction for multiple hypothesis testing. The same argument applies when multi-channel EEG is used. As counterintuitive as it may seem, the most sensitive procedure will be to select a single variable as outcome measure from a test that is known to be sensitive but unspecific. This could be (preferably a computerised measure of) performance on the Digit-Symbol Substitution Test for reasons outlined earlier in this article (see Wetherell for a review) [25], or the delayed recall performance on a word list learning paradigm as it has been showing sensitivity to druginduced changes in many different pharmacological manipulations and consistently at low doses of cholinergic[92], GABA-ergic [93], serotonergic- [94], dopaminergic [95], and glutamatergic manipulations [96]. However, such a method will obviously give poorer interpretability of the cognitive processes affected when comparing it with a test battery covering several specified cognitive domains, but this issue can be subsequently investigated using this latter more specific approach with a comprehensive or targeted cognitive test battery.

The direction of change is often important. Does a compound enhance or impair cognitive functions? In healthy volunteers it is easier to demonstrate impairment rather than improvement of cognitive or psychomotor functions. Some tests are designed to measure impairment and may have to be modified to detect improvement. An example is the 15 word list that is often used to assess declarative memory performance [97]. In the original version the list is presented 5 times each followed by an assessment of immediate recall which is after a delay of 20-30 minutes again followed by a delayed recall. Young healthy volunteers after 5 trials recall near $100 \%$ of the words and hence this procedure is not optimally designed to measure a learning or memory enhancing effect of a drug due to these so-called ceiling effects. The most used solutions are presenting the list three times instead of five, or only once [98], prolonging the list to 30 words, using a similar list of non-verbal items for subsequent recognition [99] and presenting 15 distractor words auditorily while learning 15 words presented visually [100]. All these procedures have been proven effective of detecting pharmacologically induced improvement of memory performance in healthy volunteers.

Finally, the use of prior inductions of cognitive impairment can also be employed to demonstrate evidence of drug action. Many inductions have been proposed and actually used:

\section{Pharmacological Models}

- scopolamine model of muscarinic cholinergic dysfunction [101]

- biperiden model of M1-muscarinic cholinergic dysfunction [102]

- mecamylamine model of nicotinic cholinergic dysfunction [103]

- diphenhydramine model of histaminergic/cholinergic dysfunction [104]

- benzodiazepine model of GABA-ergic dysfunction [105]

- clonidine model of noradrenergic dysfunction [106]

- alfa-methyl para-tyrosine model of noradrenergic dysfunction [107]

- tyrosine/phenylalanine depletion model of dopaminergic dysfunction [5]

- tryptophan depletion model of serotonergic dysfunction [108]

- ketamine model of glutamatergic dysfunction [109]

- 2-deoxy-glucose model of glucose depletion [110]

- ethanol model of general neural dysfunction [111]

\section{Physiological Models}

- dehydration model of general neural dysfunction [112]

- sleep deprivation model of resource depletion [26]

- physical exhaustion model of resource depletion [100]

- hypoxia model of low oxygen availability [113]

$-\mathrm{N}_{2} \mathrm{O}$ nitrogen narcosis model of low oxygen availability [114]

- hyperventilation model of low oxygen availability [115]

The classic application of an induction model consists of a hypothesised interaction of the induction and the test drug at the same time $\left(t_{\max }\right)$. Although these experimental models may have limited predictive power, in most cases there is a clear correspondence between failed results in these models and clinical success. Whereas cholinesterase inhibitors have been shown to work both in the scopolamine model and in 
the clinic in Alzheimer's Disease, muscarinic agonists have not worked well in either the scopolamine model or the clinic, which unfortunately has not been published in the literature. Overall, it is not possible to conclude on the basis of literature whether the application of pharmacological or physiological models can be used as a predictive or translational model for clinical effect. However, the utility of these models lies in the possibility to test specific hypotheses on mechanism(s) of action of investigational compounds. In addition, induction models may lower the threshold of detecting an effect in a healthy population. For example, although demonstrations of drug-induced cognition enhancement in healthy young volunteers do exist, most of those can only be obtained when subjects are in a suboptimal state prior to testing, such as is the classical example when demonstrating the procognitive effects of caffeine $[100,116]$.

\section{CONCLUDING REMARKS}

Cognitive and psychomotor performance assessment is an important pharmacodynamic measure in drug development at least since the first plea for performance assessment as part of drug registration to ensure that CNS- and non-CNS compounds are free from cognitive toxicity, now 20 years ago [14]. It has been outlined in this article that human psychopharmacology as a discipline consists of a blend of clinical neuropsychology, behaviourism, experimental psychology and cognitive science. The influence of neuroimaging will further add to that in the near future.

Properly chosen automated cognitive-test systems can speed up drug development and save money by enabling proof-of principle evaluations to be conducted at an earlier stage of development, as well as enabling efficacy to be established in pivotal trials in smaller cohorts of patients. In the right hands, properly automated and validated cognitive test systems are hugely powerful tools for drug development [17].

\section{ACKNOWLEDGEMENTS}

Mitul A. Mehta is supported by the Wellcome Trust.

\section{REFERENCES}

References 117-119 are related articles recently published in Current Pharmaceutical Design.

[1] Markowitsch H. Intellectual Functions and the Brain. An Historical Perspective. Seattle: Hogrefe \& Huber. 1992.

[2] Vermeeren A, Riedel WJ, Van Boxtel MPJ, Paty I, Darwish M, Patat A. Hangover effects of zaleplon and zopiclone on memory, psychomotor performance and actual driving: a comparison with effects of a low dose of alcohol. Sleep 2002; 25: 224-31.

[3] Spiegel R. Psychopharmacology: an introduction (3rd ed.). Chichester: John Wiley and Sons. 1995.

[4] Skinner BF. Science and Human Behaviour. New York: The Free Press. 1953.

[5] Mehta MA, Gumaste D, Montgomery AJ, McTavish SF, Grasby PM. The effects of acute tyrosine and phenylalanine depletion on spatial working memory and planning in healthy volunteers are predicted by changes in striatal dopamine levels. Psychopharmacology (Berl) 2005; 180: 654-63.

[6] Salmeron BJ, Stein EA. Pharmacological applications of magnetic resonance imaging. Psychopharmacol Bull 2002; 36: 102-29.

[7] Stein EA. fMRI: a new tool for the in vivo localization of drug actions in the brain. J Anal Toxicol 2001; 25: 419-24.
[8] Hunt E. What do we need to know about aging? In J Cerella, J Rybash, W Hoyer \& ML Commons Eds., Adult Information Processing: Limits on Loss. San Diego: Academic Press Inc. 1993; 587-598.

[9] Newell A, Simon H. Human Problem Solving. Englewood Cliffs, NJ: Prentice-Hall. 1972.

[10] Ericsson K, Simon H. Protocol Analysis. Cambridge, MA: MIT Press. 1984.

[11] Hobus P. Expertise van huisartsen. Praktijkervaring, kennis en diagnostische hypothesevorming. Maastricht: Rijksuniversiteit Limburg. 1994.

[12] Prasangsit P. Newell \& Simon: The Theory of Human Problem Solving. Retrieved 15 Dec 2004, 2004, from http://www.cc.gatech. edu/ jimmyd/summaries/newell19---2.html 1999, Mon May 3 03:02:17 EDT 1999.

[13] Sanders AF. Drugs, driving and the measurement of human performance. In JF O'Hanlon \& JJd Gier Eds., Drugs \& Driving. London: Taylor \& Francis. 1986; 3-16.

[14] O'Hanlon JF, Brookhuis KA, Louwerens JW, Volkerts ER. Performance testing as part of drug registration. In JF O'Hanlon \& JJ De Gier Eds., Drugs \& Driving. London: Taylor \& Francis. 1986; 311-330.

[15] Gaillard A. The evaluation of drug effects in laboratory tasks. In I Hindmarch, B Aufdembrinke \& H Ott Eds., Psychopharmacology and reaction time. Chichester, England: John Wiley \& Sons. 1988; 15-24.

[16] Riedel WJ, Hamers HMW, Robbe HWJ, Vermeeren A, O'Hanlon JF. Automated behavioural testing in psychotropic drug research. In LJM Mulder, FJ Maarse, WPB Sjouw \& AE Akkerman Eds., Computers in psychology: Applications in education, research and psychodiagnostics. Amsterdam, Netherlands: Swets \& Zeitlinger. 1991; 166-170.

[17] Wesnes K. Assessing cognitive function in clinical trials: latest developments and future directions. Drug Discov Today 2002; 7: 29-35.

[18] Pribram KH, McGuinness D. Arousal, activation, and effort in the control of attention. Psychol Rev 1975; 82: 116-149.

[19] Robbins T, Everitt B. Arousal Systems and Attention. In M Gazzaniga Ed., The Cognitive Neurosciences. Cambridge MA (USA): MIT Press. 1995; 703-720.

[20] Schmidt RF, Wiesendanger M. Motorische Systeme. In RF Schmidt \& G Thews Eds., Physiologie des Menschen. Berlin: Springer. 1987.

[21] Lyon M, Robbins TW. The action of central nervous system stimulant drugs: a general theory concerning amphetamine effects. In W Essman \& L Valzelli Eds., Current Developments in Psychopharmacology. New York: Spectrum. 1975; 2: 79-163.

[22] Bilder RM, Volavka J, Lachman HM, Grace AA. The catechol-Omethyltransferase polymorphism: relations to the tonic-phasic dopamine hypothesis and neuropsychiatric phenotypes. Neuropsychopharmacology 2004; 29: 1943-1961.

[23] Robbins TW. Arousal Systems and Attentional Processes. Biol Psychol 1997; 45: 57-71.

[24] Riedel WJ, Vermeeren A, Van Boxtel MPJ, Vuurman EFPM, Verhey FRJ, Jolles J, et al. Mechanisms of Drug-Induced Driving Impairment: A Dimensional Approach. Hum Psychopharmacol 1998; 13: S49-63.

[25] Wetherell A. Performance tests. Environ Health Perspect 1996; 2 : 247-73.

[26] Sanders AF. Towards a model of stress and human performance. Acta Psychologica 1983; 53: 61-97.

[27] Frowein HW, Sanders AF. Effects of amphetamine and barbiturate in a serial reaction task under paced and self-paced conditions. Acta Psychologica 1978; 42: 263-276.

[28] Warburton DM, Wesnes K. Drugs as research tools in psychology: Cholinergic drugs and information processing. Neuropsychobiology 1984; 11: 121-132.

[29] Callaway E. The pharmacology of human information processing. Psychophysiol 1983; 20: 359-371.

[30] Callaway E, Halliday R, Naylor H, Yano L, Herzig K. Drugs and human information processing. Neuropsychopharmacology 1994; 10: 9-19.

[31] Sawaguchi T, Iba M. Prefrontal cortical representation of visuospatial working memory in monkeys examined by local inactivation with muscimol. J Neurophysiol 2001; 86: 2041-53. 
[32] Revelle W. Individual differences in personality and motivation; 'non-cognitive' determinants of cognitive performance. In A Baddeley \& L Weiskrantz Eds., Attention, Selection, Awareness and Control. Oxford: Clarendon Press. 1993.

[33] Cohen JD, Dunbar K, McClelland JL. On the control of automatic processes: a parallel distributed processing account of the Stroop effect. Psychol Rev 1990; 97: 332-61.

[34] Mulder G. The concept and measurement of mental effort. In Hockey GRJ, Gaillard AWK, Coles MGH, Eds., Energetics and human information processing. Dordrecht: Martinus Nijhoff. 1986; 175-198.

[35] Kahneman D. Attention and effort. Englewood Cliffs, NJ: Prentice Hall. 1973.

[36] Norman DA, Bobrow DG. On data-limited and resource-limited processes. Cognitive Psychology 1975; 7: 44-64.

[37] Mattay VS, Berman KF, Ostrem JL, Esposito G, Van Horn JD, Bigelow LB, et al. Dextroamphetamine enhances "neural networkspecific" physiological signals: a positron-emission tomography rCBF study. J Neurosci 1996; 16: 4816-4822.

[38] Cools R, Robbins TW. Chemistry of the adaptive mind. Philos Transact A Math Phys Eng Sci 2004; 362: 2871-2888.

[39] Mehta MA, Owen AM, Sahakian BJ, Mavaddat N, Pickard JD, Robbins TW. Methylphenidate enhances working memory by modulating discrete frontal and parietal lobe regions in the human brain. J. Neurosci 2000; 20: RC65:1-6.

[40] Weingartner H, Eckardt M, Molchan S, Sunderland T, Wolkowitz O. Measurement and interpretation of changes in memory in response to drug treatments. Psychopharmacol Bull 1992; 28: 331340.

[41] Robbins TW, James M, Owen AM, Sahakian BJ, McInnes L, Rabbitt P. Cambridge Neuropsychological Test Automated Battery (CANTAB): a factor analytic study of a large sample of normal elderly volunteers. Dementia 1994; 5: 266-81.

[42] Robbins TW, James M, Owen AM, Sahakian BJ, Lawrence AD, McInnes L, et al. A study of performance on tests from the CANTAB battery sensitive to frontal lobe dysfunction in a large sample of normal volunteers: implications for theories of executive functioning and cognitive aging.Cambridge Neuropsychological Test Automated Battery. J Int Neuropsychol Soc 1998; 4: 474-90.

[43] Wesnes KA, Ward T, McGinty A, Petrini O. The memory enhancing effects of a Ginkgo biloba/Panax ginseng combination in healthy middle-aged volunteers. Psychopharmacology 2000; 152: 353-361.

[44] Sternberg S. Memory scanning: mental processes revealed by reaction time experiments. Am Scient 1969; 57: 421-457.

[45] Sanders AF. Energetics, Stress and Sustained Attention. In AF Sanders Ed., Elements of Human Performance. New Jersey: Lawrence Erlbaum Associates. 1998; 394-451.

[46] Parrott AC. Performance tests in human psychopharmacology: I. Test reliability and standardization. Hum Psychopharmacol 1991; 6: 1-9.

[47] Parrott AC. Performance tests in human psychopharmacology: II. Content validity, criterion validity, and face validity. Hum Psychopharmacol 1991; 6: 91-98.

[48] Parrott AC. Performance tests in human psychopharmacology: III. Construct validity and test interpretation. Hum Psychopharmacol 1991; 6: 197-207.

[49] Rosnow RL, Rosenthal R (Eds.). People studying people. Artifact and Ethics in behavioural research. New York, NY: W. H. Freeman \& Co. 1997.

[50] Green JB, Elder WW, Freed DM. The P1 component of the middle latency auditory evoked potential predicts a practice effect during clinical trials in Alzheimer's disease. Neurology 1995; 45: 962-966.

[51] Wesnes K, Pincock C. Practice effects on cognitive tasks: a major problem? Lancet Neurol 2002; 1: 473.

[52] Stein RA, Strickland TL. A Review of the Neuropsychological Effects of Commonly Used Prescription Medications. Arch Clin Neuropsychol 1998; 13: 259-284.

[53] Hindmarch I. Psychomotor function and psychoactive drugs. Br J Clin Pharmacol 1980; 10: 189-209.

[54] Riedel WJ, Van Praag HM. Avoiding and Managing Anticholinergic Effects of Antidepressants. CNS Drugs 1995; 3: 245-259.

[55] King DJ, Henry G. The effect of neuroleptics on cognitive and psychomotor function. A preliminary study in healthy volunteers. Br J Psychiatry 1992; 160: 647-53.
[56] Meltzer HY, McGurk SR. The effects of clozapine, risperidone, and olanzapine on cognitive function in schizophrenia. Schizophr Bull 1999; 25: 233-55

[57] Curran HV. Benzodiazepines, memory and mood: A review. Psychopharmacology 1991; 105: 1-8.

[58] Vermeeren A. Residual effects of hypnotics: epidemiology and clinical implications. CNS Drugs 2004; 18: 297-328.

[59] Shamsi Z, Hindmarch I. Sedation and Antihistamines: A Review of Inter-Drug Differences using Proportional Impairment Ratios. Hum Psychopharmacol Clin Exp 2000; 15: 3-30S.

[60] Geyer MA, Tamminga CA. Measurement and treatment research to improve cognition in schizophrenia: neuropharmacological aspects. Psychopharmacology 2004; 174: 1-2.

[61] Marder SR, Fenton W, Youens K. Schizophrenia, IX: Cognition in schizophrenia--the MATRICS initiative. Am J Psychiatry 2004; 161: 25 .

[62] Green MF, Nuechterlein KH. The MATRICS initiative: developing a consensus cognitive battery for clinical trials. Schizophr Res 2004; 72: 1-3.

[63] Nuechterlein KH, Barch DM, Gold JM, Goldberg TE, Green MF, Heaton RK. Identification of separable cognitive factors in schizophrenia. Schizophr Res 2004; 72: 29-39.

[64] Marder SR, Fenton W. Measurement and Treatment Research to Improve Cognition in Schizophrenia: NIMH MATRICS initiative to support the development of agents for improving cognition in schizophrenia. Schizophr Res 2004; 72: 5-9.

[65] Green MF, Nuechterlein KH, Gold JM, Barch DM, Cohen J, Essock S, et al. Approaching a consensus cognitive battery for clinical trials in schizophrenia: the NIMH-MATRICS conference to select cognitive domains and test criteria. Biol Psychiatr 2004; 56: 301-7.

[66] Lowe C, Rabbitt P. Test/re-test reliability of the CANTAB and ISPOCD neuropsychological batteries: theoretical and practical issues. Neuropsychologia 1998; 36: 915-923.

[67] Hockey GRJ. Changes in operator efficiency as a function of environmental stress, fatigue, and circadian rhythms. In KR Boff, L Kauffman \& JP Thomas Eds., Handbook ofPerception and Human Performance. New York: Wiley. 1986; 2: 44-49.

[68] Biomarkers, Definitions, Working, Group. Biomarkers and surrogate endpoints: preferred definitions and conceptual framework. Clin Pharmacol Ther 2001; 69: 89-95.

[69] Kramer AF. Physiological metrics of mental workload: a review of recent progress. In DL Damos Ed., Multiple Task Performance. London: Taylor and Francis 1991.

[70] Kapur S. Relationship between dopamine D(2) occupancy, clinical response, and side effects: a double-blind PET study of firstepisode schizophrenia. Am J Psychiatr 2000; 157: 514-520.

[71] Tracey I. Prospects for human pharmacological functional magnetic resonance imaging (phMRI). J Clin Pharmacol 2001; Suppl: 21S-28S.

[72] Honey G, Bullmore E. Human pharmacological MRI. Trends Pharmacol Sci 2004; 25: 366-74.

[73] Arthurs OJ, Stephenson CM, Rice K, Lupson VC, Spiegelhalter DJ, Boniface SJ, et al. Dopaminergic effects on electrophysiological and functional MRI measures of human cortical stimulus-response power laws. Neuroimage 2004; 21: 540-6.

[74] Wilhelm H. Pupillenreaktionen, Pupillenstoerungen. Stuttgart: Kohlhammer 1991.

[75] Unema P. Eye movements and mental Effort. Berlin: Technical University. 1995.

[76] Van der Molen MW, Bashore TR, Halliday R, Callaway E. Chronopsychophysiology. In RJ Jennings \& MG Coles Eds., Handbook of psychophysiology. New York: Wiley \& Sons 1991.

[77] Luczak H. Psychophysiologische Methoden zur Erfassung psychophysische Beanspruchungs-zustände. In Arbeitspsychologie, Band D/III/1, Enzyklopädie der Psychologie. Göttingen: Hogrefe Verlag 1987.

[78] Casali JG, Wierwille WW. On the measurement of pilot perceptual workload: a comparison of assessment techniques addressing sensitivity and intrusion issues. Ergonomics 1984; 27: 1033-50.

[79] Gent W. Volumenpulscurven bei Gefühlen und Affecten. Wundt Philosophische Studien 1903; 18: 715-792.

[80] Mulder G. The heart of mental effort. Unpublished Dissertation, Univ of Groningen The Netherlands. 1980.

[81] Jennings JR. Do cardiovascular changes indicate energetic support of information processing? In GRJ Hockey, AWK Gaillard \& 
MGH Coles Eds., Energetics and human information processing. Dordrecht: Martinus Nijhoff Publishers. 1986.

[82] Aasman J, Mulder G, Mulder LJ. Operator effort and the measurement of heart-rate variability. Special Issue: Cognitive psychophysiology. Hum Fac 1987; 29: 161-170.

[83] Mulder LJ. Measurement and analysis methods of heart rate and respiration for use in applied environments. Biol Psychol 1992; 34: 205-36.

[84] Egelund N. Spectral analysis of heart rate variability as an indicator of driver fatigue. Ergonomics 1982; 25: 663-72.

[85] Frankenhaeuser M. Psychoneuroendocrine approaches to the study of emotion as related to stress and coping. In HE Howe \& RA Dienstbier Eds., Nebraska symposium on motivation 1968. Lincoln: Nebraska Press. 1979; 123-161.

[86] Lundberg U, Frankenhaeuser M. Psychophysiological reactions to noise as modified by personal control over noise intensity. Biol Psychol 1978; 6: 51-9.

[87] Fibiger W, Singer G. Biochemical assessment and differentiation of mental and physical effort. Work and Stress 1989; 9: 237-247.

[88] Mason JW. Organization of Psychoendocrine Mechanisms. In NS Greenfield \& RA Sternbach Eds., Handbook of Psychophysiology. New York: Holt, Rinehart and Winston. 1972; 3-17.

[89] Bassett JR, Marshall PM, Spillane R. The physiological measurement of acute stress (public speaking) in bank employees. Int J Psychophysiol 1987; 5: 265-73.

[90] O'Hanlon JF, Swijgman HF, Vermeeren A. Comparison of alpidem, lorazepam and placebo effects in a combined clinical/psychometric study: a new approach for assessing the behavioural costs and benefits of anxiolytic drug therapy. In $G$ Bartholini, M Garreau, PL Morselli \& B Zivkovic Eds., Imidazopyridines in anxiety disorders: a novel and therapeutic approach. New York: Raven Press. 1993.

[91] O'Hanlon JF, Vermeeren A, Uiterwijk MMC, Van Veggel LMA, Swijgman HF. Anxiolytics' Effects on the Actual Driving Performance of Patients and Healthy Volunteers in a Standardized Test. An Integration of Three Studies. Neuropsychobiology 1995; 31: 81-88.

[92] Wesnes K, Simpson P, Kidd A. An investigation of the range of cognitive impairments induced by scopolamine $0.6 \mathrm{mg}$ s.c. Hum Psychopharmacol 1988; 3: 27-41.

[93] Vermeeren A, Jackson JL, Muntjewerff ND, Quint PJ, Harrsison EM, O'Hanlon JF. Comparison of acute alprazolam $(0.25,0.50$ and $1.0 \mathrm{mg}$ ) effects versus those of lorazepam $2 \mathrm{mg}$ and placebo on memory in healthy volunteers using laboratory and telephone tests. Psychopharmacology 1995; 118: 1-9.

[94] Riedel WJ, Klaassen T, Deutz NEP, Van Someren A, Van Praag HM. Tryptophan Depletion in Normal Volunteers Produces Selective Impairment in Memory Consolidation. Psychopharmacology 1999; 141: 362-369.

[95] Rammsayer TH, Rodewald S, Groh D. Dopamine-antagonistic, anticholinergic, and GABAergic effects on declarative and procedural memory functions. Brain Res Cogn Brain Res 2000; 9: 61-71.

[96] Newcomer JW, Farber NB, Jevtovic-Todorovic V, Selke G, Melson AK, Hershey T, et al. Ketamine-induced NMDA receptor hypofunction as a model of memory impairment and psychosis. Neuropsychopharmacology 1999; 20: 106-118

[97] Rey A. L'examen psychologique dans les cas d'encéphalopathie traumatique. Paris: Presses Universitaires de France 1964.

[98] Tildesley NT, Kennedy DO, Perry EK, Ballard CG, Savelev S, Wesnes KA, et al. Salvia lavandulaefolia (Spanish sage) enhances memory in healthy young volunteers. Pharmacol Biochem Behav 2003; 75: 669-74.

[99] Schmitt JAJ, Jorissen BL, Dye L, Markus CR, Deutz NEP, Riedel WJ. Memory function in women with premenstrual complaints and the effect of serotonergic stimulation by acute administration of an alpha-lactalbumin protein. J. Psychopharmacol 2005; 19: 375-384.

[100] Hogervorst E, Riedel WJ, Kovacs E, Brouns F, Jolles J. Caffeine improves cognitive performance after strenuous physical exercise. Int J Sports Med 1999; 20: 354-361.

[101] Wesnes KA, Simpson PM, White L, Pinker S, Jertz G, Murphy M, et al. Cholinesterase inhibition in the scopolamine model of dementia. Ann N Y Acad Sci 1991; 640: 268-71.

[102] Wezenberg E, Verkes RJ, Sabbe BGC, Ruigt GSF, Hulstijn W. Effects of Biperiden and Rivastigmine on memory and visuospatial processes. Retrieved 16 march, 2005, from http://www.enpmeeting. nl/enp/enp2004/speakers/thursday/Wezenberg.pdf 2004

[103] Newhouse PA, Potter A, Corwin J, Lenox R. Age-Related Effects of the Nicotinic Antagonist Mecamylamine on Cognition and Behaviour. Neuropsychopharmacology 1994; 10: 93-107.

[104] Oken BS, Kishiyama SS, Kaye JA, Howieson DB. Attention deficit in Alzheimer's disease is not simulated by an anticholinergic/ antihistaminergic drug and is distinct from deficits in healthy aging. Neurology 1994; 44: 657-62.

[105] Duka T, Ott H, Rohloff A, Voet B. The effects of a benzodiazepine receptor antagonist beta-carboline ZK-93426 on scopolamineinduced impairment on attention, memory and psychomotor skills. Psychopharmacology 1996; 123: 361-73.

[106] Smith A, Brice C, Nash J, Rich N, Nutt DJ. Caffeine and central noradrenaline: effects on mood, cognitive performance, eye movements and cardiovascular function. J Psychopharmacol 2003; 17: 283-92.

[107] McCann UD, Penetar DM, Shaham Y, Thorne DR, Gillin JC, Sing HC, et al. Sleep deprivation and impaired cognition. Possible role of brain catecholamines. Biol Psychiatry 1992; 31: 1082-97.

[108] Riedel WJ. Cognitive changes after Acute Tryptophan Depletion; What can they tell us? Psychol Med 2004; 34: 3-8.

[109] Krystal JH, D'Souza DC, Mathalon D, Perry E, Belger A, Hoffman R. NMDA receptor antagonist effects, cortical glutamatergic function, and schizophrenia: toward a paradigm shift in medication development. Psychopharmacology (Berl) 2003; 169: 215-33.

[110] Breier A, Davis OR, Buchanan RW. Alprazolam attenuates metabolic stress-induced neuroendocrine and behavioural effects in humans. Psychopharmacology 1991; 104: 479-84.

[111] Nilsson LG, Backman L, Karlsson T. Priming and cued recall in elderly, alcohol intoxicated and sleep deprived subjects: a case of functionally similar memory deficits. Psychol Med 1989; 19: 42333.

[112] Neave N, Scholey AB, Emmett JR, Moss M, Kennedy DO, Wesnes KA. Water ingestion improves subjective alertness, but has no effect on cognitive performance in dehydrated healthy young volunteers. Appetite 2001; 37: 255-6.

[113] Weinachter SN, Blavet N, O'Donnell RA, MacKenzie ET, Rapin JR. Models of hypoxia and cerebral ischemia. Pharmacopsychiatry 1990; 23: 94-7.

[114] Fowler B, Hofer K, Lipitkas J. The exhaustive additivity displayed by nitrous oxide has implications for cognitive-energetical theory. Biol Psychol 2000; 52: 161-80.

[115] Van Diest I, Stegen K, Van de Woestijne KP, Schippers N, Van den Bergh O. Hyperventilation and attention: effects of hypocapnia on performance in a stroop task. Biol Psychol 2000; 53: 233-52.

[116] van Duinen H, Lorist MM, Zijdewind I. The effect of caffeine on cognitive task performance and motor fatigue. Psychopharmacology (Berl) 2005; 180: 539-47.

[117] Carreiras MC, Marco JL. Recent approaches to novel antiAlzheimer therapy. Curr Pharm Des 2004; 10(25): 3167-75.

[118] Marcinko L, Read M. Cognitive therapy for schizophrenia: treatment and dissemination. Curr Pharm Des 2004; 10(18): 2269-75.

[119] Rose GM, Hopper A, De Vivo M, Tehim A. Phosphodiesterase inhibitors for cognitive enhancement. Curr Pharm Des 2005; 11(26): 3329-34. 